\title{
Return of the mummy
}

\section{An ancient Egyptian priest has a virtual life at London's British Museum.}

\section{Michael Hopkin}

Three thousand years ago, the people of Karnak, an ancient Egyptian community on the banks of the Nile, embalmed and buried a priest called Nesperennub. They did a good job - he has remained mummified ever since and is unlikely ever to be unwrapped. But now we can at last say hello, face to virtual face, thanks to a project that blends archaeology, medical technology and computer graphics.

The practice of unwrapping - and thus destroying - mummies was rife when Nesperennub was delivered into the collection of London's British Museum in 1899. But Nesperennub has survived to become the centrepiece of Mummy: the Inside Story, an exhibition that runs at the museum until January 2005. The exhibition showcases the museum's new non-invasive approach to studying wrapped mummies, using computerized tomography (CT) scanners of the sort common in hospitals.

John Taylor, the museum's egyptologist who led the project, teamed up with the imaging company Silicon Graphics (SGI) to reconstruct Nesperennub from some 1,500 CT images, as shown here. This is the first time that CT scans have been used to reveal a mummy's intimate details previous attempts using X-rays provided only sketchy images.

The new technique has sparked fresh speculation about Nesperennub's life and death, and confirms some long-held theories about the mummification process. The brain is missing, for example, as are the fine bones of the nasal cavity - a vindication of archaeologists' belief that the brain was removed by pulling it through the nose. Elsewhere, vital organs such as the lungs and liver have been removed, wrapped and replaced. Nesperennub's body is adorned with amulets, presumably to safeguard his passage to the world of the gods.

Judging by the wear and tear on his backbone, Nesperennub lived into his forties. And as his 1.62metre stature attests, he was probably well fed. But life wasn't an endless round of pleasure: it seems he had a large abscess under one of his teeth; and a hole in his skull, apparently made from the inside, hints that he died of a brain tumour. The

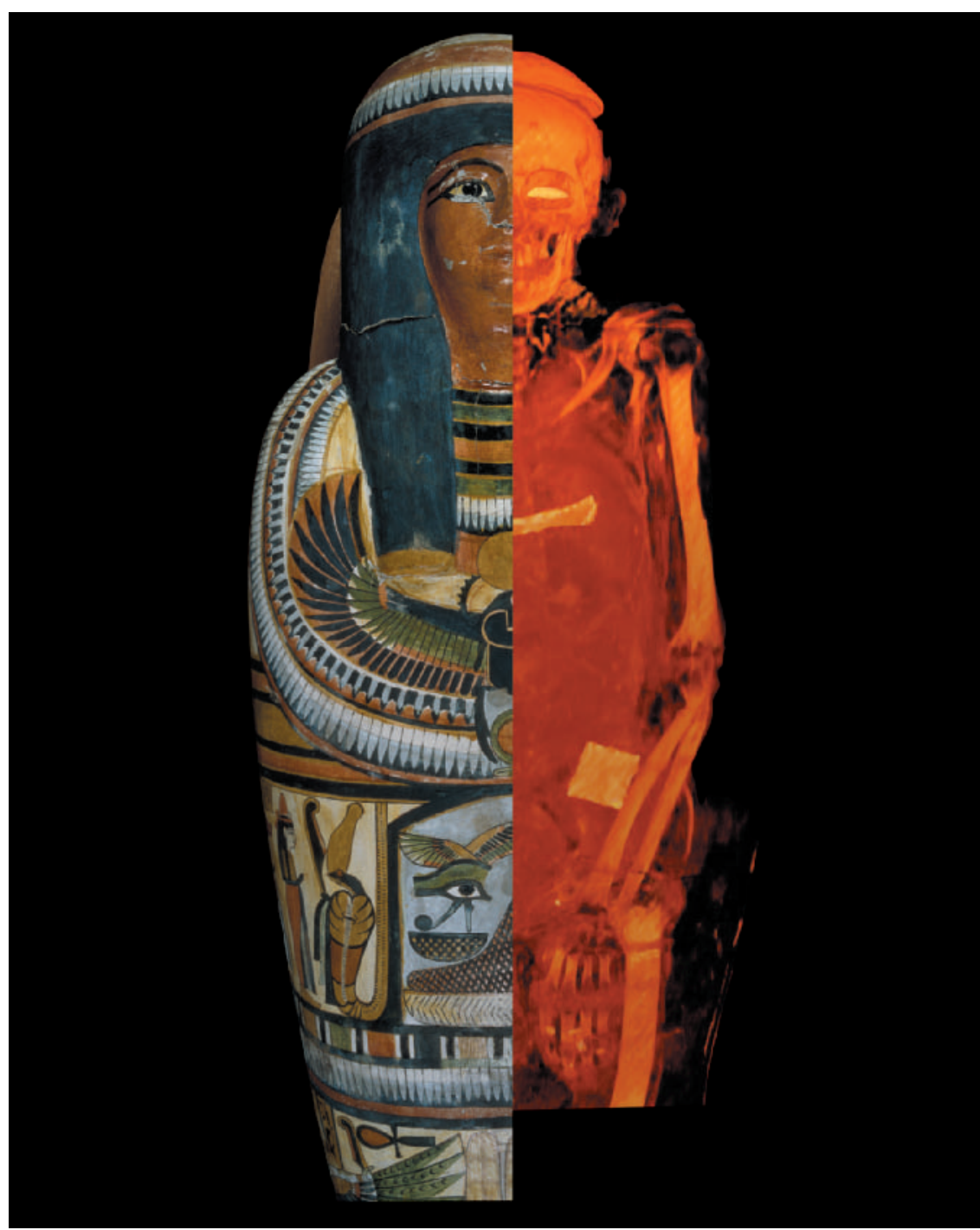

project's members have even created a virtual bust of Nesperennub, although they admit that facial reconstructions always involve a measure of guesswork.

Most intriguingly of all, however, Nesperennub has a clay bowl seemingly stuck to the top of his head. Unlike the rest of his adornments, it is not ornately carved. Taylor speculates that it may have been placed there to catch drips of embalming resin and accidentally become stuck fast.
Visitors to the museum can ponder this possibility as they watch a film featuring computer reconstructions and scenes from everyday life in Karnak, as envisaged by the project team. Entertaining, yes. But Taylor emphasizes that the technique is first and foremost a research tool - the museum has about 100 mummies in its collection, and plans to bring many of them back to virtual life. Michael Hopkin writes for news@nature.com,

Nature's online news service. noticed that what works for three sets seems to work less well for four, and might break down entirely for five or more sets, when perhaps our enthusiasm for classification begins to fade. Is there an elegant way of drawing a Venn diagram showing all possible intersections of, say, seven sets, and is it systematic - does it build routinely to an arbitrary number of sets?

What Cogwheels of the Mind triumphantly shows is that the answer to both questions is 'yes'. A.W. F. Edwards not only shows how it can be done, but discusses a variety of different solutions that connect Venn diagrams to significant questions in coding theory. $\mathrm{He}$ also provides a fascinating glimpse into how research into mathematics gets done, and tells a satisfying historical story. And he provides what may be the most important reason for continuing to care about these diagrams: they illuminate the problem of finding maximal embeddings of subgraphs of a hypercube. All this and a great number of mathematically beautiful figures mean that the book deserves to become a minor classic and may well go on to make many friends for mathematics.

Jeremy Gray is at the Centre for the History of the Mathematical Sciences, Open University, Milton Keynes MK7 6AA, UK. 